Jörg Strübing

Qualitative Sozialforschung 



\section{Jörg Strübing}

Qualitative

Sozialforschung

Eine komprimierte Einführung

2., überarbeitete und erweiterte Auflage

OLDENBOURG 
ISBN 978-3-11-052991-3

e-ISBN (PDF) 978-3-11-052992-0

e-ISBN (EPUB) 978-3-11-053015-5

\section{Library of Congress Cataloging-in-Publication Data}

Names: Strübing, Jörg, author.

Title: Qualitative Sozialforschung : eine komprimierte Einführung für Studierende / Jörg Strübing.

Description: 2., überarbeitete und erweiterte Auflage. | Boston/Berlin : De Gruyter, [2018] | Series: Soziologie kompakt

Identifiers: LCCN 2018007274| ISBN 9783110529913 (softcover : alk. paper) | ISBN 9783110529920 (PDF) | ISBN 9783110530155 (EPUB)

Subjects: LCSH: Social sciences--Research--Methodology. | Qualitative research.

Classification: LCC H62 .S7868 2018 | DDC 300.72/1--dc23 LC record available at https://lccn.loc.gov/2018007274

\section{Bibliografische Information der Deutschen Nationalbibliothek}

Die Deutsche Nationalbibliothek verzeichnet diese Publikation in der Deutschen Nationalbibliografie; detaillierte bibliografische Daten sind im Internet über http://dnb.dnb.de abrufbar.

(C) 2018 Walter de Gruyter GmbH, Berlin/Boston Einbandabbildung: ipopba/iStock/Getty Images Plus Satz: Meta Systems Publishing \& Printservices GmbH, Wustermark Druck und Bindung: $\mathrm{CPI}$ books $\mathrm{GmbH}$, Leck

www.degruyter.com 
Für Harry, dem ich mehr verdanke, als er sich wohl vorstellen kann. 
